\title{
Identity Work: Enactment of Ethnic-Racial Identity in Everyday Life
}

\author{
William E. Cross, Jr. ${ }^{\text {a }}$, Eleanor Seaton ${ }^{\mathrm{b}}$, Tiffany Yip $^{\mathrm{c}}$, Richard M. Lee ${ }^{\mathrm{d}}$, Deborah Rivas ${ }^{\mathrm{d}}$, \\ Gilbert C. Gee ${ }^{\mathrm{e}}$, Wendy Roth ${ }^{\mathrm{f}}$, and Bic Ngo ${ }^{\mathrm{g}}$ \\ ${ }^{\mathrm{a}}$ Department of Counseling Psychology, University of Denver, Denver, Colorado, USA; ${ }^{\mathrm{b}}$ The Stanford \\ School, Arizona State University, Tempe, Arizona, USA; 'Department of Psychology, Fordham \\ University, New York, New York, USA; dDepartment of Psychology, University of Minnesota,

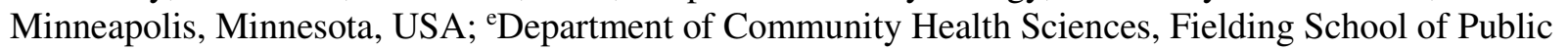 \\ Health, University of California, Los Angeles, Los Angeles, California, USA; 'Department of Sociology, \\ University of British Columbia, Vancouver, British Columbia, Canada; ' ${ }^{\mathrm{D}}$ Department of Curriculum and \\ Instruction, University of Minnesota, Minneapolis, Minnesota, USA
}

This is an Accepted Manuscript of an article published by Taylor \& Francis in Identity in 2017, available online at:

http://dx.doi.org/10.1080/15283488.2016.1268535

Please cite as:

Cross, William E., Jr., Eleanor Seaton, Tiffany Yip, Richard M. Lee, Deborah Rivas, Gilbert C. Gee, Wendy Roth and Bic Ngo. 2017. "Identity Work: Enactment of RacialEthnic Identity in Everyday Life." Identity 17(1): 1-12. 


\begin{abstract}
In this theoretical analysis, we discuss the attributional and enactment approaches to identity and present a new Ethnic-Racial Identity Enactment Model derived from extant theory and research. We highlight modes of identity work that provide 1) self-concept and self-esteem protection; 2) achievement and success during everyday encounters; 3) a sense of belonging and attachment to one's ascriptive group; and 4) the relation between internalized oppression and internalized racism in everyday exchanges. We discuss the integration of self-concept mechanisms with mindsets and intentions specific to ethnic-racial identity dynamics. The article ends by highlighting a research procedure that fuses the attributional and enactment approaches to identity research.
\end{abstract}


Identity Work: Enactment of Racial-Ethnic Identity in Everyday Life

In 2012 a task force consisting primarily of developmental psychologists met for the first time at Brown University for the purpose of conducting an in-depth analysis of theory and research on ethnic-racial identity[ERI]. Verkuyten (2016) subsequently referenced the task force as the "Study Group." Their activities resulted in the production of a four article special issue of Child Development (2014), and the first addressed methodological concerns (Schwartz et al, 2014), a second covered outcomes associated with ERI development (Rivas-Drake, et al, 2014a), a third conducted a meta-analysis between ERI and various outcomes (Rivas-Drake et al., 2014b) and a fourth presented a new integrated conceptualization of ERI development (Umaña-Taylor, et al, 2014). In the Study Group's integrated model for ERI development covering infancy through adolescence, personal identity and social identity development were interwoven to the point that little separation was made between the two. However, taking a cue from French and colleagues (2007) on the differences between the two, Verkuyten (2016) made the case for continuation and extension of the Study Group's activities by approaching ERI primarily from a social identity perspective, where ERI is a social identity more than a personal identity phenomenon. While ERI development from the personal identity perspective highlights the "being," "feeling", and "knowing" aspects of human development (e.g., ERI as an "intrapsychic" construct), a social identity perspective adds these otherwise overlooked elements: ethnic behavior and identity enactments (Verkuyten, 2005). It was to assist in the development of this line of theorizing and research that Gaines and colleagues (2016) created the Brunel Ethnic Behavior Inventory (BEBI).

Following the production of the four ERI articles for the special issue of Child Development, the Study Group reconvened, and in anticipation of Verkuyten's call for a shift in focus, turned their attention to ERI as something enacted, accomplished, and managed during 
daily interactions (Brekhus, 2008). The make-up of the reconvened Study Group was more interdisciplinary, and this is reflected in our title. The concept "identity work" is derived from the field of sociology in general, and Goffman's writings in particular, on the way members of stigmatized groups attempt to manage one's stigma status through a crafted and highly intentional presentation of self in everyday life. (Goffman, 1959)

We define ethnic-racial identity (ERI) as "a multidimensional, psychological construct that reflects the beliefs and attitudes that individuals have about their ethnic-racial group memberships, as well as the process by which these beliefs and attitudes develop over time" (Umaña-Taylor et al., 2014, p. 23). In this paper, we build upon this conceptualization of ERI to propose a model of how ERI is experienced, lived and enacted in daily life. Specifically, extending our earlier work, we propose ERI is more than a label, category, or set of attributes. ERI is enacted in everyday life as a set of behavioral and psychological negotiations.

\section{Foundational Theories}

The enactment related theoretical writings of Oyserman and Destin (2010), Boykin (1986), Stevenson (2014), and Cross, Smith and Payne (2002) will be reviewed, culminating in the construction of an integrative model of ERI enactments. Brekhus (2003, p. 17) observed that context has the power to elicit conduct such as "how to feel, how to act and even how to "be". Oyserman and Destin's (2010) identity-based motivation model incorporates Susan T. Fiske's (1992) notion that thinking is for doing. Their model underscores how people use identity to make sense of the world around them, their place in it, and, more importantly, to prepare for action in situations that upon successful negotiation result in the fulfillment of one's motivational needs, desires and wants. 
It is unrealistic for a theory to account for every single identity-setting. We limit our discussion to how parents socialize and children to live in a racialized world. This focus is chosen given the many studies that document the messages and themes that Black parents in particular (Burt, Simons, \& Gibbons, 2012; Miller, 1999; Miller \& MacIntosh, 1999; Scott, 2003; Thomas \& Speight, 1999), and minority parents in general (Hughes, 2003; Hughes et al., 2006; Quintana \& Vera, 1999; Spencer \& Markstrom-Adams, 1990), transmit as part of the ethnic-racial socialization process. In ethnic-racial socialization processes, parents cultivate in their progeny a "mindset" for the types of identity-settings and experiences likely to be encountered as a consequence of one's ascribed race/ethnicity.

Boykin (1986) developed a three-tiered model, the Triple Quandary Theory, of the perspective that racial/ethnic parents attempt to inculcate in progeny. Boykin stressed the need for identity performance within three contexts labeled threat, mainstream, and community. Boykin's Triple Quandary Theory explains that from each context emanates both denigrative as well as supportive messaging. Despite the quandary, the person seeks to successfully negotiate each situation in accordance to her/his needs, wants, and desires. The first theme, "threat", involves discriminatory settings that pose a threat to the person's identity and in some cases (e.g., being stopped by the police) lead to harm or even death (Boykin, 1986). Quandary and perplexity enter the picture because one can imagine other contexts where the same person may seek the assistance of the same police force. "Mainstream" the second theme, involves having one's educational, employment or health care needs met within mainstream institutions that have less than a stellar track record servicing, educating or caring for members of one's group (Boykin, 1986). One example includes sending one's child to a school with a poor track record of educating children of color. In this situation, a parent will try to help the child develop a 
mindset for extracting and learning race-neutral knowledge controlled by the school and its teachers. The third theme, "community", is somewhat unique. Boykin (1986) argued that one can be a member of an ethnic-racial group, whereas development of a positive group identity is something one learns and acquires. The quandary is the way internalized racism influences attitudes and actions of individuals from one's respective racial/ethnic group.

The diunital dynamics of Boykin's (1986) discourse highlights the dilemmas associated with enacting a flexible and positive sense of self across multiple settings, which simultaneously include positive and negative messages. Second, Boykin's theory underscores agency rather than victimization. Khanna (2011) argued that an identity work perspective helps students and scholars consider marginalized groups as active agents, rather than passive actors in the face of dominant forces. Specifically, active agents shape the contours and inner-dynamics of ethnicracial identity through their thinking, actions, and creativity. Stevenson (2014) created a K-12 curriculum promoting ethnic/racial literacy in schools because he wanted minority youth to understand that even when they feel pressured in a given situation, one's response may exacerbate or defuse situational dynamics.

The identity enactment model constructed by Cross, Smith and Payne (2002) overlaps considerably with Boykin's Triple Quandary Theory (1986). In their model Cross, Smith and Payne (2002):

1. Differentiate intergroup from intragroup dynamics that help explicate distinctions to be made between stigma management from cultural identity management;

2. Integrate notions of biculturalism and hybridity in depicting enactments taking place within mainstream contexts; 
3. Accord greater importance to internalized racism and internalized oppression than is true of the Boykin model;

4. Perceive each enactment type as a node in an otherwise reticulated psychological web. The web connectors help explain, how, given dynamic shifts in the situation, a person can switch from one mindset to another; and they use the phrase "identity enactment repertoire" to capture the enactment system as a whole.

\section{A New Ethnic-Racial Identity Enactment Model}

We present a new summative model that integrates key conceptualizations (see Figures 1 and 2). We adopt the enactment nosology developed by Cross, Smith, and Payne (2002): Buffering, Code-switching, Bridging, Attachment-Bonding, Internalized racism, and Individuality. The first set of enactments (buffering, code-switching, and bridging), explore the intergroup dynamics of ERI enactments. Buffering and code switching are central to Goffman's notion of stigma management (Goffman, 1959). The second set of enactments (attachmentbonding and internalized racism) occur in intragroup settings and represent reference group management strategies. Individuality is included at the end of Figure 2, and captures the personal identity component of the self that acts in tandem with social identity, as discussed by French et al (2007), Cross (1991), and Verkuyten (2016). Below we provide a description of each type of enactment, beginning with the way a person frames and perceives the identity setting and then explication of the intent triggered by the setting. Next we describe the behaviors, outcomes, consequences as well as any quandaries embedded within the situation. At the end of each segment, we insert research complimenting the enactment narrative.

Buffering. Settings related to buffering are experienced as threatening to one's psychological integrity and possibly one's physical well-being. The person often finds 
him/herself in a reactive stance, as the event is generally initiated by someone else and ongoing by the time the person can accurately "frame" it. The task becomes "buffering" oneself from the full thrust of the insult, which means to prevent it from taking full effect - to "blunt" and reduce the sting, hurt, or pain. Thus while complete shielding may be impossible, buffering is a realistic outcome. Implicit bias and microaggressions are hard to detect and can make buffering very difficult to execute. The more developed one's ego and general self-concept skills, the more psychological resources one brings to the threat encounter (Brekhus 2003). Buffering combined with cultural awareness seems to produce greater buffering capacity (Quintana and Vera 1999). Positive outcomes are enhanced self-esteem, an intact though shaken core identity and maintenance of physical and mental health. Part of the dilemma of being a member of a stigmatized group is that a social actor may be a threat in one context, and a source of protection and support in another (Boykin 1986).

Considerable research shows the protective benefit of ethnic-racial identity. In one of the first applications of the widely-used Rosenberg Self-Esteem Scale, a survey of nearly 2000 Black and White high school students conducted in the late 1960s, Rosenberg and Simmons (1971) reported that Black students exhibited average levels of self-esteem despite awareness of the larger society's preference for whites. However, the Black students made a distinction between societal preference, as differentiated from beauty standards and self-acceptance derived from the Black community's ethos and aesthetics. Crocker and Major (1989) conducted studies that theorized, predicated, and demonstrated stigma self-protection. Their research explicated multiple mechanisms members of stigmatized groups employ when transacting encounters with stigma: awareness and appraisal of the source; use of an in-group point of reference; and devaluation. When the target is aware of the existence of discriminatory persons and contexts 
(i.e., anticipatory mindset) and at the point of encounter is able to appraise the person or context as biased, this awareness or mindset can buffer self-esteem (Crocker \& Major, 1989). Replicating the finding by Rosenberg and Simons (1971), Crocker and Major (1989) also found that the use of the in-group as a source for standards about one's personal worth is also important for protecting against standards imposed by biased "others". Crocker and Major (1989) noted that identity and self-concept protection is afforded when the stigmatized person simply discounts the value and importance of the standards or judgments being advocated by the biased person or context.

Code-Switching (CS). CS sites are perceived by the ethnic-racial person as mainstream institutions where basic desires, wants and needs can be fulfilled, as long as the person transacts relationships, performs tasks or demonstrates mastery in accordance to the culture, norms and expectations of the mainstream institution (Oyserman and Destin, 2010; Cross, Smith and Payne, 2002). CS is generally linked to intentional strategies and the planned behavior initiated by the ethnic-racial person unlike buffering settings which involve happenstance. Thus, whether going to a bank to apply for a car loan or home mortgage, attending school to attain a degree, seeking health care assistance from a hospital, or attending a TIAA-CREF retirement seminar, the person frames the situation as a site where one displays and performs bicultural competence such that key players in the situation will act to satisfy the person's motivations. The person "temporarily" enacts behavioral codes of the mainstream group with the hope that in demonstrating one's capacity and motivation to "fit-in," the manager, teacher or physician will see the person as just another student, patient, or employee. Just as immigrants experience acculturation stress, it may be that members of ethnic-racial groups experience CS-stress. The big picture is one of acculturation or mastery of the "others" "way of doing things, and those adept at doing so exhibit 
significant bicultural competence (cf. Berry, 2001). The minority person often experiences the transactions in phases: 1) preparing for entrance into the mainstream that may involve dress, appearance and overall presentation of self; 2) actual entrance and "performance" within the mainstream as student, employee, or client such that the "other" provides a service or meets a need; and 3) exit from the mainstream and reentry into one's home, sometimes followed by debriefing with loved ones, husband, children and kin. As a result of CS, the person satisfies needs, such as employment, attainment of a degree or certificate, letters of reference, completion of a major commercial venture, receipt of quality health care, etc. The person often has knowledge that the institution in question has a questionable track record in treating, educating, or serving members of his ethnic-racial group yet his/her choices are limited and she/he will push forward anyway. This is likely because the outcomes dependent on biculturally competent engagement with such institutions are significant for the person's life chances.

Studies show that when particular ERI expressions are in conflict with mainstream expectations for success, the empirical literature suggests that individuals generate strategies to cope with such conflict (Carter, 2005; Gibson, 1988, 2005; Padilla, 2006). Specifically, bicultural competence is often defined in terms of the successful reconciliation of conflicting behavioral expectations, as when the expected values are endorsed and language or style is expressed in each sphere (e.g., Carter, 2005; Zhou \& Bankston, 1998), and thus multiple, competing codes are effectively managed. For individuals where ERI involves membership in multilingual communities, code-switching involves "the alternating use of two or more 'codes' within a single conversational episode" (Auer, 1998, p. 1; see also Gumperz, 1982; Myers-Scotton, 1993). The switch occurs at any level of language differentiation, such as languages, styles, and dialects (Myers-Scotton, 1993). Code-switching is an expression of ERI that uses language to "construct 
and display multiple identities, to understand their historic position, and to respond to relations of domination between groups" (Gal, 1988, p. 247). Language shifting is a rather demonstrative exemplar of CS; however, Cross, Smith and Payne (2002) point to the subtle and less obvious shifts that come with concern for one's hair style, facial cosmetic choice, attire, mannerisms, which taken as a whole better capture Goffman's thesis of the sensitivity to one's presentation of self in everyday life often exhibited by members of ERI groups (Goffman, 1959).

Bridging. Despite the pain of buffering experiences and the hassles accompanying mainstream transactions, some ethnic-racial members experience friendship and even intimacy across interracial boundaries. Bridging reflects identity settings where intergroup contacts and friendships are transacted. Bridging has a transcendent quality as the parties perceive themselves to have made a basic connection involving their fundamental humanity. Rather than silenced, denied, or made invisible, differences are usually part and parcel of the friendship; part of the attraction is the other's difference. There is nothing automatic about this process and the ethnicracial minority person has to be "open" to such encounters. The ability to be open and vulnerable to effectuating associations across social barriers defines bridging intent. If buffering and code-switching are at the foundation of one's stigma management skills, bridging is a wonderful relief from having to be "on-guard" in interactions and exchanges with the "other." Sometimes tension is felt by the ethnic-racial minority member for being open and vulnerable to a person who is member of a group that has historically caused pain and suffering to one's reference group. Consequently, there can be anxiety for letting one's guard down. Such boundary crossing may trigger animus from members of one's own group. In mainstream situations where the ratio of minority to majority is in the extreme, the ability to bridge to a member of the dominant group can make the difference in job security, treatment within a 
hospital or attainment of a degree, because the friend may run interference or keep one informed about roadblocks ahead, as she/he has inside information that comes from being a member of the mainstream. Research: [Insert brief summary of research findings here]

Buffering, code-switching and bridging generally reflect intergroup dynamics. Buffering and code-switching are at the heart of one's stigma management skills, because identity protection and need fulfillment result from successful transactions with the "other". However, intergroup relations are not the sole province of ethnic-racial identity enactment theory. Varied, strong and positive intragroup interactions are the basis of a strong, positive sense of belonging to one's socially ascribed group. At birth one may be accorded nominal status with a social group or groups, but racial-ethnic identity results from activities that explore and effectuate attachment and bonding to one's group, its history, its challenges, and its culture.

Attachment-Bonding (AB): Just as a child evolves a deep and lasting sense of being human through attachment exchanges with a key caretaker, an individual achieves belonging, affiliation and commitment to one's ethnic-racial group as a consequence of repeated bonding and belonging experiences. $\mathrm{AB}$ generally involves intentionality until habituation is achieved, at which point awareness of the enactment may become subliminal. When $\mathrm{AB}$ forms the basis of one's aesthetics, a whole series of leisure time choices and artistic purchases will emanate from one's conception of beauty and joy. Boykin (1956) believes group identification is taken for granted and overly normalized rather than understood to be the result of intentionality and identity work. AB involves identity work because it does not unfold automatically, as it requires knowledge, practice, choices and perspective. This perspective is reflected in Tatum's (2003) observation that not every parent seeks to inculcate a sense of ethnic-racial belonging in their progeny, leading to identity salience and identity centrality. AB combined with artistic talent can 
result in cultural productions. For example, when the self-concept of the individual person includes creative skills and talents, identification can motivate her or him to produce poetry, novels, music, painting, sculpture, etc. In understanding how $\mathrm{AB}$ is linked to the production of cultural products, it is important to note that ethnic-racial minorities cannot escape the influence of mainstream culture, and hybridity and cultural duality are often revealed in their artistic attachment-bonding creations. For example, jazz is performed on instruments of European origin and the core of a jazz aesthetic is the fusion of chords and melodies from European musical traditions combined with syncopation readily tracked to Africa. Research: [Insert brief summary of research findings here]

Internalized Racism and Oppression (IRO). A fraction of ethnic-racial minority members accept the negative societal beliefs and stereotypes about themselves (Williams \& Williams-Morris, 2000). Thus, internalized racism and internalized oppression are part of the identity work thesis. Forms of IRO can vary from negative attitudes that result in miseducation (learning negative facts about one's group that are inaccurate) to acceptance of views regarding the superiority/inferiority of skin color (e.g., colorism). Burgeoning research has indicated that having a defined ethnic/racial identity is linked to a lower likelihood of endorsing stereotypical attitudes of African Americans regarding beauty standards and eating behaviors (Cotter, Kelly, Mitchell \& Mazzeo, 2015; Henrickson, Crowther \& Harrington, 2010; Zhang, Dixon \& Conrad, 2009). Furthermore, previous research generally supported the idea that having a strong and developed ethnic/racial identity mitigates the activation of stereotype threat among minority group members (Abdou \& Fingerhut, 2014; Armenta, 2010; Ho \& Sidanius, 2009; Van Laar, Levin \& Sinclair, 2008). 
Individuality. What is the nature and quality of an ascribed person's experience when she/he is not enacting race or ethnicity? Strauss and Cross (2005) answered this question with the enactment category "individuality" meant to depict shifting to a mindset of just being oneself. Including it as part of their study of enactments in a daily diary study illustrated that the African American research participants reported spending more time just being oneself than enacting race (Strauss \& Cross, 2005). Typically, the other people present were other blacks and when whites were present, there was a greater probability that the target person perceived self, others and setting through a racial lens (Strauss \& Cross, 2005). Thus, while the category individuality is not an ethnic-racial enactment experience, its inclusion illustrates when ethnicity or race is or is not being enacted.

Cross, Smith and Payne (2002) offer additional intragroup categories that are beyond the scope of our analysis. For example, they note that buffering and code-switching can take on “collective" dynamics. Organizations such as B'nai B'rith or the NAACP serve the purpose of surveillance in order to ferret out discrimination before it happens and to provide support for those ensnarled by a discriminatory action. In a similar fashion, affinity groups can facilitate professional code-switching such as the Black Caucus for SRCD, or Silicon Valley's dev/color, a nonprofit organization that supports minority software developers and engineers (Guynn, 2016). We return to the concept of collective buffering at a later point.

\section{Self-concept, Personality and Identity Content.}

When theorizing ethnic-racial identity dynamics, one's explanation for the relationship between identity-content specific to each group and universal components of the self-concept is particularly important. For example, Brekhus - a proponent of an enactment approach to identity - has this to say about identity specificity and self-concept properties: 
"Individuals have a package of multiple identity characteristics and they may foreground different parts of that package depending on the site or time in which they are situated. They may engage in microtemporal shifts of identity from one setting to the next, playing up different facets of their self to match different temporal and spatial context" (2003, p. 17).

Brekhus's perspective overlaps with Cross, Smith and Payne's (2002) concept of structural reticulation where each enactment modality (buffering, code switching, etc.) is conceived as a node with strands extending outward and connecting all nodes in spider-web like structure. For heuristic purposes, we presented each enactment modality separately even though the connectors in the web help explain how the modalities interface, as when an identity setting starts off as a code switching encounter but quickly shifts to a buffering situation, given a key actor says something racist. Strauss and Cross (1998) recorded such instantaneous switching in their daily diary study of racial enactments.

In addition, Brekhus' theorizing links enactments to ego and personality (Brekhus, 2003). After a person "frames" the situation and moves toward intent and action, her/his actual performance will be influenced by personality proclivities, personality style and individuality. One's universal personality dynamics come into to play in the coping styles and personality that scaffold the way the person executes her/his intentions. A shy, reserved and hesitant person will enact buffering and code switching differently from a person who is forward, self-confident, gregarious, and slightly aggressive. The presentation of self for one is to be small, unnoticed and as invisible as possible while the other has a presence no matter the situation.

\section{Synthesizing Attributes and Enactments.}

Enactment theory and research has a strong foothold in sociological circles with origins traceable to Erving Goffman's seminal work, "The Presentation of Self in Everyday Life" 
(Goffman, 1959). This has led to the production of case studies anchored in long, rich narrations such as Wayne Brekhus' study of gay enactments in suburban settings (Brekhus, 2003) or Nikki Khanna's (2011) study of biracial identity, focusing on how biracial individuals form and perform racial identity. In psychology, the preference is for methods that divide human activity into more quantifiable chunks translated as variables and factors (Khanna, 2011) and, the attributional approach to the study of ethnic-racial identity is voluminous. Swim, Cohen and Hyers (1998) have developed and refined a methodology that combines narrative and attributional approaches. In studies focusing on critical incidences of racism and sexism, where 'incident' matches closely what we call identity-setting, Swim and colleagues created an incident report form and a participant is first instructed to write a brief narrative describing the incident and from there he/she answers a series of question to deconstruct her/his experience, using checklists and Likert Scale responses (Swim et al., 1998). The deconstruction component allows reporting on how many people were present, what were some of their characteristics, a description of the setting, the emotions expressed by the people present, whether or not the target person initiated the activity, a description of the target person's state of mind and affect, etc. The Swim Incident Report Form fuses elements of attributional psychology with enactment theory. Strauss and Cross (2005) made use of this mixed method procedure in a study of racial identity enactments in everyday life as reported by 35 African American college students (29 females and 6 males) attending a predominantly white university located in Northeast sector of the United States. Each student recorded one enactment per day for 15 days and the study as a whole produced 525 enactment reports. After writing a brief description of the enactment experience, the follow up deconstruction items explored five domains: 1. type of identity transaction used in the situation (buffering, code switching; bridging; bonding and acting as an 
individual); 2. number and characteristics of people present; 3. perceived racial salience of one's mindset; 4. affective valance for the event as a whole; and 5. self-perceived level of stress. A combination of OLS and HLM statistical procedures were used to produce creates profiles for buffering, code-switching, bridging and individualism. The profiles captured times when the person believed s/he was enacting race or simply being her/himself. The vast majority of enactments reported fell into this last category meaning that across a 15-day period, the participants spent a great deal of time just being themselves, and not, necessarily, enacting race. Otherwise the rank order of frequency of enactments for Buffering, Code Switching, Attachment Bonding and Bridging was 3, 4, 2, 5 respectively. In his social commentary on race and identity titled "The content of our character", Shelby Steele (1990) tries to make the case that ERI development may suppress the expression of one's individuality; however, the results from the study by Strauss and Cross (2005) suggest ERI youth balance ERI and individuality, at a ratio favoring the expression and enactment of individuality.

\section{Concluding Remarks}

The Ethnic-Racial Identity Enactment Model presented here attempts to explicate identity work associated with five types of identity settings: situations of threat (identity work as buffering); mainstream identity settings (identity work as code-switching); situations leading to

friendship or even intimacy across ethnic/racial boundaries (identity work as bridging); situations that reinforce belonging and bonding to one's reference group (identity work as attachment \& bonding); situations that undermine a positive sense of self (identity work as internalize oppression); and finally situations that allow the person to simply be themselves (situations that allow the expression of one's individuality). We linked buffering and code switching to the hassle, annoyance and outright oppressive aspects of being part of a stigmatized group, captured 
by the phrase "stigma management" generally transacted through intergroup interactions. We emphasized the paradoxical nature of the buffering and code switching transactions, as key actors in the setting can in one instance be the source of threat, danger and oppression and in another a caring policeman, supportive teacher or professor, empowering manager or concerned health care specialist. We suggested that the level of ethnic/racial literacy exhibited by the ethnic/racial minority group member can by their mindset, personality style, and intentions go a long way in determining how the interactional episode will unfold and in this sense the identity work perspective helps one better appreciate the level of agency ethnic-racial persons bring to any identity work transaction. Although our discourse highlighted relations between the powerful and the marginalized, we made certain to give due weight to those aspects of identity work related to the attachment and bonding to one's reference group. We also isolated identity work associated with ethnic-racial psychological vulnerability lived and expressed as internalized racism. Finally, we made note of the interesting finding from the study of Straus and Cross (2005) showing that over a period of time, members of a marginalized group reported transacting ethnic-racial enactments $24 \%$ of the time with the majority of their time and life experience spent just "being themselves".

It was necessary to address the interface of enactments and what are termed the universal aspects of the self-concept. We concluded that while the mindsets resulting from being racially literate are culturally unique, the actual performance of one's mindset, no matter how culturally grounded, is carried out with psychological dynamics, traits and ego mechanism commonplace to all humankind.

We end our presentation with an example of collective buffering. On June $19^{\text {th }} 2015$, nine Black adults were shot and killed in Charleston, South Carolina as they participated in Bible 
study. During the investigation of the murderer's past, photos were uncovered of him waving and displaying the infamous Confederate Flag, a racist symbol made popular during massive Southern white resistance to desegregation and voting rights during the1950s, 1960s and 1970s. A few days after the shooter was captured, a news report showed him peering out the window of a small room designed to let a person hear the comments of people stationed on the opposite side of the glass partition. In this instance, the people present were relatives of the murdered adult African American men and women. The relatives expressed compassion and forgiveness for the shooter who sat quietly, during this phenomenal enactment of collective buffering. Despite the young shooter's horrific actions, they were the first to recognize and affirm his humanity. In giving the eulogy for one of the victims, President Barak Obama captured this courageous and extraordinary display of collective humanism, religiosity and spirituality, with a rendition of the song, Amazing Grace. The actions of the relatives rippled across the nation and inspired local white politicians to take up the cause of removing the Confederate flag, then prominently positioned on the South Carolina state government campus. A distant relative of Jefferson Davis, the former president of the Confederacy, pleaded with members from both sides of the political spectrum to enact legislation to remove the flag. This is an exemplar of how identity work meant to buffer racial-ethnic group members subsequently made possible positive racial identity work enacted by Whites. 
Table 1: Intergroup Enactments: Stigma Management

\begin{tabular}{|c|c|c|c|}
\hline Enactment & Identity setting & Motivation & Quandary \\
\hline Buffering & $\begin{array}{l}\text { Threat: Bias } \\
\text { discrimination, } \\
\text { ranging from } \\
\text { barely detectable } \\
\text { microaggressions } \\
\text { to threat of bodily } \\
\text { harm }\end{array}$ & $\begin{array}{l}\text { When impossible to avoid, } \\
\text { motivation is to keep threat from } \\
\text { having full effect, to blunt, to } \\
\text { buffer as in take some of the } \\
\text { "sting" out of the assault; intent } \\
\text { is to save face, to maintain self- } \\
\text { esteem, to exit unharmed even if } \\
\text { one has to eat a little crow; } \\
\text { when possible, offer a defense } \\
\text { or counter narrative }\end{array}$ & $\begin{array}{l}\text { Source may have the } \\
\text { power to fulfill a } \\
\text { need in other } \\
\text { circumstances yet in } \\
\text { "the moment" is } \\
\text { executing the power } \\
\text { to hurt and do } \\
\text { psychological or even } \\
\text { physical damage }\end{array}$ \\
\hline Code-Switching & Mainstream & $\begin{array}{l}\text { To fulfill one's need for health } \\
\text { care, education, banking, etc. } \\
\text { that can only be fulfilled in } \\
\text { interaction with mainstream } \\
\text { institutions and their } \\
\text { representatives (e.g., teachers, } \\
\text { bank officials, care salesman, he } \\
\text { health care providers) }\end{array}$ & $\begin{array}{l}\text { Institution and or } \\
\text { representatives may } \\
\text { have record of poor } \\
\text { treatment or bias } \\
\text { while providing } \\
\text { service; unless } \\
\text { treatment is over the } \\
\text { top, person will } \\
\text { persist until } \\
\text { transaction is } \\
\text { complete to one's } \\
\text { satisfaction (e.g., car } \\
\text { loan or home } \\
\text { mortgage is executed, } \\
\text { medical treatment is } \\
\text { fulfilled) }\end{array}$ \\
\hline Bridging & $\begin{array}{l}\text { Friendship or } \\
\text { intimacy across } \\
\text { group boundaries }\end{array}$ & $\begin{array}{l}\text { Develop trust, friendship and } \\
\text { even intimacy with person who } \\
\text { belongs to a social group with a } \\
\text { track record of executing bias } \\
\text { and harm toward one's reference } \\
\text { group }\end{array}$ & $\begin{array}{l}\text { To trust and be } \\
\text { vulnerable versus } \\
\text { avoid, reject } \\
\text { overtures, hold back } \\
\text { or remain guarded }\end{array}$ \\
\hline
\end{tabular}


Table 2: Intragroup Enactments: Reference Group Management

\begin{tabular}{|c|c|c|c|}
\hline Enactment & Identity setting & Motivation & Quandary \\
\hline $\begin{array}{l}\text { Attachment- } \\
\text { Bonding }\end{array}$ & $\begin{array}{l}\text { Intragroup } \\
\text { Activities }\end{array}$ & $\begin{array}{l}\text { Strengthen one's sense of } \\
\text { belonging to the reference group; } \\
\text { increase one's knowledge about } \\
\text { the group; one's authorship (poet, } \\
\text { novel, historical text, etc.) or } \\
\text { performance (singer, instrument, } \\
\text { actor, etc.) that reproduces or } \\
\text { sustains the groups' social } \\
\text { representation; basis for one's } \\
\text { meaning in life }\end{array}$ & $\begin{array}{l}\text { Deference and sense } \\
\text { of obligation to the } \\
\text { group versus push- } \\
\text { pull of one's } \\
\text { individuality; lure of } \\
\text { another reference } \\
\text { group }\end{array}$ \\
\hline $\begin{array}{l}\text { Internalized } \\
\text { racism and } \\
\text { internalized } \\
\text { oppression }\end{array}$ & $\begin{array}{l}\text { Race-ethnicity } \\
\text { related bias } \\
\text { exhibited by } \\
\text { oneself, often } \\
\text { during } \\
\text { exchange with } \\
\text { another } \\
\text { member of } \\
\text { one's } \\
\text { reference } \\
\text { group }\end{array}$ & $\begin{array}{l}\text { Cause hurt, pain or insult to one's } \\
\text { self-image and or to direct } \\
\text { psychological insult to another }\end{array}$ & $\begin{array}{l}\text { Overall the person's } \\
\text { ethnic-racial self- } \\
\text { image may be more } \\
\text { positive than negative } \\
\text { but negative thoughts } \\
\text { about the self may } \\
\text { limit the person's } \\
\text { vision of what is } \\
\text { possible }\end{array}$ \\
\hline $\begin{array}{l}\text { Personal } \\
\text { identity }\end{array}$ & Individuality & $\begin{array}{l}\text { Expression of the self from the } \\
\text { vantage point of one's personality } \\
\text { rather than any particular reference } \\
\text { group orientation. }\end{array}$ & $\begin{array}{l}\text { At times person may } \\
\text { be torn between being } \\
\text { true to oneself versus } \\
\text { a sense of obligation } \\
\text { to the group as in } \\
\text { personal motivations } \\
\text { versus reference } \\
\text { group needs. }\end{array}$ \\
\hline
\end{tabular}




\section{References}

Abdou, C.M. \& Fingerhut, A.W. (2014). Stereotype threat among Black and White women in healthcare settings. Cultural Diversity and Ethnic Minority Psychology, 20, 316-323.

Armenta, B.E. (2010). Stereotype boost and stereotype threat effects: The moderating role of ethnic identification. Cultural Diversity and Ethnic Minority Psychology, 16, 94-98.

Boykin, A Wade. (1986). The triple quandary and the schooling of Afro-American children. The school achievement of minority children: New perspectives, 57-92.

Brekhus, Wayne H. (2003). Peacocks, chameleons, centaurs: Gay suburbia and the grammar of social identity: university of Chicago Press.

Brekhus, Wayne H. (2008). Trends in the qualitative study of social identities. Sociology Compass, 2(3), 1059-1078.

Burt, Callie Harbin, Simons, Ronald L, \& Gibbons, Frederick X. (2012). Racial discrimination, ethnic-racial socialization, and crime a micro-sociological model of risk and resilience. American Sociological Review, 77(4), 648-677.

Cotter, E.W., Kelly, N.R., Mitchell, K.S. \& Mazzeo, S.E. (2015). An investigation of body appreciation, ethnic identity, and eating disorder symptoms in Black women. Journal of Black Psychology, 41, 3- 25.

Crocker, Jennifer, \& Major, Brenda. (1989). Social stigma and self-esteem: The self-protective properties of stigma. Psychological review, 96(4), 608-630.

Cross, W. E., Jr., (1991). Shades of black. Philadelphia: Temple University Press.

Cross Jr, W. E, Jr., Smith, L., \& Payne, Y. (2002). Black identity: A repertoire of daily enactments. Counseling across cultures, 5, 93-107.

Cross, W. E., Jr., \& Strauss, L. (1998). The everyday functions of African American identity. In J. K. Swim (Ed.), (1998). Prejudice: The target's perspective (pp. 267-279). San Diego, CA: Academic Press, Inc.

Fiske, Susan T. (1992). Thinking is for doing: portraits of social cognition from daguerreotype to laserphoto. Journal of Personality and Social Psychology, 63(6), 877.

Gaines Jr, S. O., Lefringhausen, K., Charura, D., Kangatharan, J., Singh, J., Tamimi, N., Dieu, K., Knap, S., Towers-Evans, H., \& Zahara, S. (2016). Ethnic Speech and Ethnic Action as Ethnic Behavior: Part 1. Construction of the Brunel Ethnic Behavior Inventory. Identity, 16(2), 73-86.

Guynn, J. (2016). Silicon Valley's black engineers get big assistZ: spftware engineers start a thriving support netweor. USA Today, Section B, pp. 5B, Monday, October 3, 2016.

Goffman, E. (1959). The presentation of self in everyday life Garden City. Doubleday.

Henrickson, H.C., Crowther, J.H. \& Harrington, E.F. (2010). Ethnic identity and maladaptive eating: Expectancies about eating and thinness in African American women. Cultural Diversity and Ethnic Minority Psychology, 16, 87-93.

Ho, A.K. \& Sidanius, J. (2009). Preserving positive identities: Public and private regard for one's ingroup and susceptibility to stereotype threat. Group Processes \& Intergroup Relations, 13, 55-67.

Hughes, Diane. (2003). Correlates of African American and Latino parents' messages to children about ethnicity and race: A comparative study of racial socialization. American Journal of Community Psychology, 31(1-2), 15-33. 
Hughes, Diane, Rodriguez, James, Smith, Emily P., Johnson, Deborah J., Stevenson, Howard C., $\&$ Spicer, Paul. (2006). Parents' ethnic-racial socialization practices: A review of research and directions for future study. Developmental Psychology, 42(5), 747-770.

Khanna, Nikki. (2011). Ethnicity and race as 'symbolic': the use of ethnic and racial symbols in asserting a biracial identity. Ethnic and Racial Studies, 34(6), 1049-1067.

Klein, O., Spears, R., and Reicher, S. (2007). Social identity performance: Extendingthe strategic side of SIDE. Personality and Social Psychology Review, 11, 28-45.

Miller, David B. (1999). Racial socialization and racial identity: Can they promote resiliency for African American adolescents? Adolescence, 34(135), 493.

Miller, David B, \& MacIntosh, Randall. (1999). Promoting resilience in urban African American adolescents: Racial socialization and identity as protective factors. Social work research, 23(3), 159-169.

Oyserman, Daphna, \& Destin, Mesmin. (2010). Identity-based motivation: Implications for intervention. The Counseling Psychologist, 38(7), 1001-1043.

Quintana, Stephen M., \& Vera, Elizabeth M. (1999). Mexican American children's ethnic identity, understanding of ethnic prejudice, and parental ethnic socialization. Hispanic Journal of Behavioral Sciences, 21(4), 387-404.

Rivas-Drake, D., Seaton, E. K., Markstrom, C., Quintana, S., Syed, M., Lee, R. M., Schwartz, S., Umaña-Taylor, A. J., \& Yip, T. (2014). Ethnic and racial identity in adolescence:

Implications for psychosocial, academic, and health outcomes. Child Development, 85(1), 40-57.

Rosenberg, Morris, \& Simmons, R. . (1971). The Urban School Child. Washington, DC: American Sociological Association.

Scott, Lionel D. (2003). The relation of racial identity and racial socialization to coping with discrimination among African American adolescents. Journal of Black Studies, 33(4), 520-538.

Schwartz, S. J., Syed, M., Yip, T., Knight, G. P., Umaña-Taylor, A. J., Rivas-Drake, D., \& Lee, R. M. (2014). Methodological issues in ethnic and racial identity research with ethnic minority populations: Theoretical precision, measurement issues, and research designs. Child development, 85(1), 58-76.

Spencer, Margaret Beale, \& Markstrom-Adams, C. (1990). Identity processes among racial and ethnic minority children in America. Child Development, 61, 290-310.

Strauss, LC, \& Cross Jr, William E. (2005). Transacting Black identity: A two-week daily-diary study. Navigating the future: Social identity, coping, and life tasks, 67-95.

Steele, S. (1990). The content of our character (Vol. 60). New York: St. Martin's Press.

Swim, Janet K., Cohen, Laurie L., \& Hyers, Lauri L. (1998). Experiencing everyday prejudice and racism. In J. K. Swim \& C. Stangor (Eds.), Prejudice: The target's perspective (pp. 37-60). San Diego, CA,US: Academic Press, Inc.

Tatum, Beverly. (2003). Why Are All the Black Kids Sitting Together in the Cafeteria?: Revised Edition: Basic Books.

Thomas, Anita Jones, \& Speight, Suzette L. (1999). Racial identity and racial socialization attitudes of African American parents. Journal of Black psychology, 25(2), 152-170.

Umaña-Taylor, Adriana J., Quintana, Stephen M., Lee, Richard M., Cross, William E., RivasDrake, Deborah, Schwartz, Seth J., . . . Racial Identity in the 21st Century Study, Group. (2014). Ethnic and Racial Identity During Adolescence and Into Young Adulthood: An Integrated Conceptualization. Child Development, 85(1), 21-39. doi: 10.1111/cdev.12196 
Van Laar, C., Levin, S. \& Sinclair, S. (2008). Social identity and personal identity stereotype threat: The case of affirmative action. Basic and Applied Social Psychology, 30, 295310.

Verkuyten, M. (In press: 2016). Further conceptualizing ethnic and racial identity research: The social identity approach and its dynamic model. Child Development. DOI: 10.1111/cdev,.12555

Williams, D. R., \& Williams-Morris, R. (2000). Racism and mental health: The African American experience. Ethnicity \& Health, 5, 243-268.

Zhang, Y., Dixon, T.L. \& Conrad, K. (2009). Rap Music Videos and African American Women's Body Image: The Moderating Role of Ethnic Identity. Journal of Communication, 59, 262-278. 